Epidemiology and Infection

cambridge.org/hyg

\section{Original Paper}

Cite this article: Liu CY, Chai SJ, Watt JP (2020). Communicable disease among people experiencing homelessness in California. Epidemiology and Infection 148, e85, 1-10. https://doi.org/10.1017/S0950268820000722

Received: 11 October 2019 Revised: 29 January 2020

Accepted: 26 February 2020

\section{Key words:}

Infectious disease; people experiencing homelessness; public health; vulnerable populations

Author for correspondence:

J. P. Watt, E-mail: James.Watt@cdph.ca.gov

\title{
Communicable disease among people experiencing homelessness in California
}

C. Y. Liü ${ }^{1}$ S. J. Chai ${ }^{2,3}$ (D) and J. P. Watt ${ }^{2}$

${ }^{1}$ Kaiser Permanente San Francisco/University of California San Francisco Internal Medicine/Preventive Medicine Residency, San Francisco, USA; ${ }^{2}$ Division of Communicable Disease Control, California Department of Public Health, Richmond, California, USA and ${ }^{3}$ Career Epidemiology Field Officer Program, Division of State and Local Readiness, Center for Preparedness and Response, Centers for Disease Control and Prevention, Atlanta, Georgia, USA

\begin{abstract}
California has a large population of people experiencing homelessness (PEH) that is characterised by a high proportion of people who are unsheltered and chronically homeless. $\mathrm{PEH}$ are at increased risk of communicable diseases due to multiple, intersecting factors, including increased exposures, comorbid conditions including substance use disorder and mental illness and lack of access to hygiene and healthcare facilities. Data available for several communicable diseases show that PEH in California experiences an increased burden of communicable diseases compared to people not experiencing homelessness. Public health agencies face unique challenges in serving this population. Efforts to reduce homelessness, increase access to health care for $\mathrm{PEH}$, enhance data availability and strengthen partnerships among agencies serving $\mathrm{PEH}$ can help reduce the disparity in communicable disease burden faced by $\mathrm{PEH}$.
\end{abstract}

\section{Homelessness in the USA and in California}

The definition of a person experiencing homelessness (PEH) differs by government agency. The US Department of Health and Human Services defines a homeless individual as one who 'lacks housing', which includes 'an individual whose primary residence during the night is a supervised public or private facility that provides temporary living accommodations and an individual who is a resident in transitional housing' [1]. The US Department of Housing and Urban Development (HUD) expands the definition to include people living in unstable housing arrangements such as motels, personal vehicles, and tents [2]. Causes of homelessness include lack of affordable housing, unemployment, poverty, and low wages [3].

Measuring the number of $\mathrm{PEH}$ is challenging, as housing status can fluctuate over time. One method of measurement is an unduplicated one-night estimate of sheltered and unsheltered individuals who are experiencing homelessness. In the USA, this is conducted yearly during the last week in January by local planning bodies [4]. In 2018, this measurement identified $553000 \mathrm{PEH}$ in the USA, of which 180000 (33\%) were individuals who are part of families with children. Of the total, $65 \%$ were sheltered (living in shelters or motels) and $60 \%$ were men. [4] From 2010 to 2018, the number of PEH declined by $13.2 \%$ nationally, but increased by $5.3 \%$ in California.

California's population of $\mathrm{PEH}$ is distinctive due to its size, the proportion of unsheltered individuals and proportion of chronically homeless individuals (defined as a person who is continuously homeless for greater than 1 year, or greater than four episodes of homelessness in 3 years [5]). In 2018, California accounted for 12\% of the US population (40 million) [6] and $24 \%$ of the total population of $\mathrm{PEH}$ (129972, or $0.3 \%$ of California's population) [4] (Fig. 1). Los Angeles County, California's largest county by population, accounts for $25 \%$ of California's total population and 32\% of California's homeless population (42 079) (Fig. 2). Nearly half $(47 \%)$ of the US unsheltered homeless population lives in California and more than two-thirds (69\%) of California's homeless population is unsheltered (Fig. 3). Finally, 32668 chronically homeless individuals live in California, representing 25\% of all PEH in California and $37 \%$ of the US population of chronically homeless individuals [4].

Mortality is increased among PEH compared to the general population, especially among younger people and women [7]. A study of homeless youth (15-24 years) in San Francisco reported an age, race and gender-adjusted standardised mortality ratio of 10.6 (95\% CI (5.3-18.9)) compared with California's general youth population [8]. Individuals who are unsheltered or chronically homeless have further increased risk of mortality [9]. Unsheltered PEH has a 2.7-fold increased risk of mortality compared to those who are sheltered [10]. Increased mortality is related to a number of causes including poisoning (medication and illicit substances), suicides, accidents, heart disease, and infections. Increased infection-specific mortality among $\mathrm{PEH}$ has been documented, although data are limited because of the difficulties in capturing information on PEH. Studies of human 
Fig. 1. California population of persons experiencing homelessness (PEH).
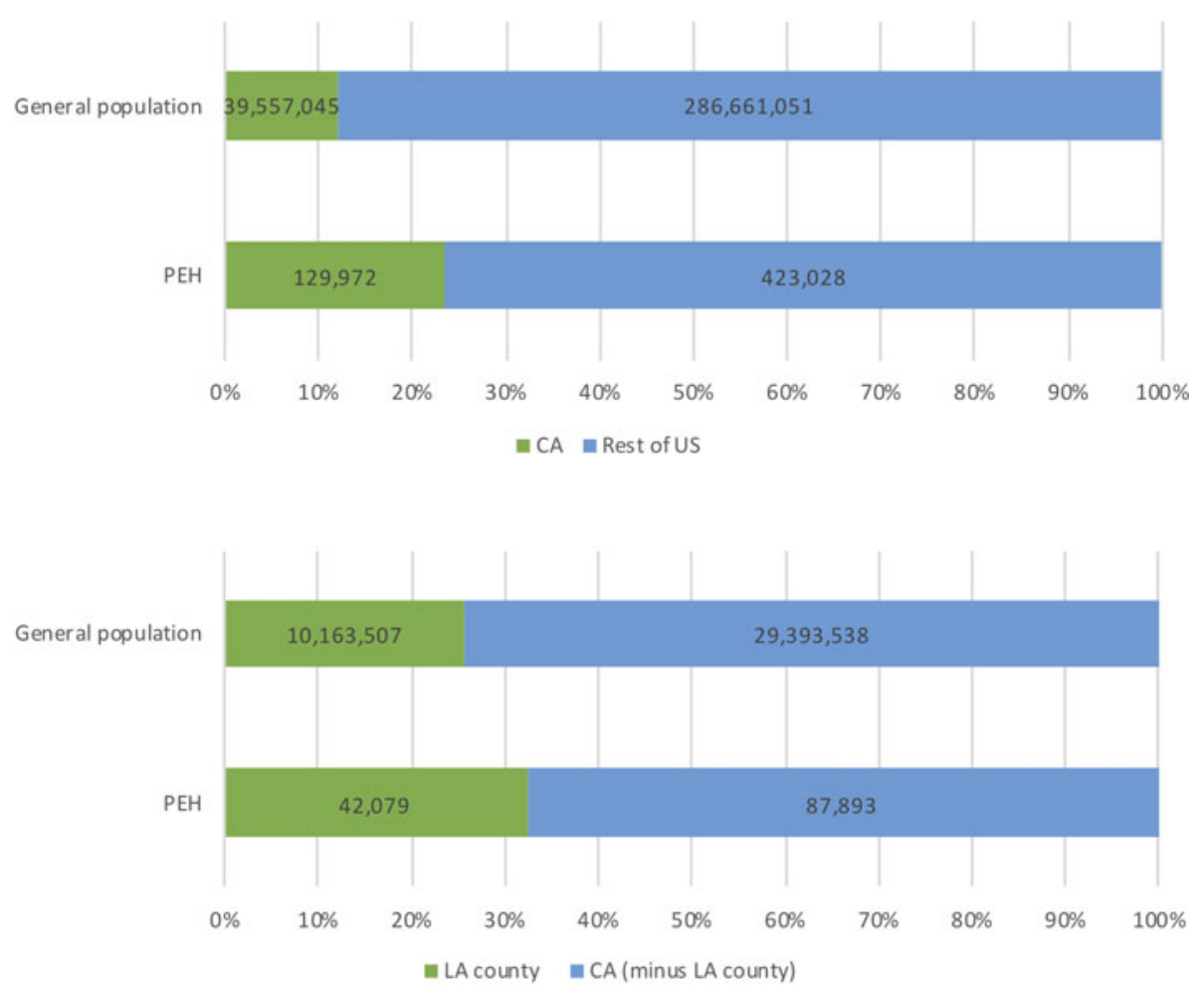

Fig. 2. Los Angeles County population of persons experiencing homelessness (PEH). increases exposures to pathogens transmitted via faecal-oral transmission such as hepatitis A [16] and may increase exposure to vectors such as lice, which can transmit Bartonella quintana infections [17]. Inadequate hygiene facilities may also worsen minor wounds due to lack of adequate skin care $[18,19]$. $\mathrm{PEH}$ may also have comorbid substance use disorders or engage in risky sexual behaviour, which can increase the risk of acquisition of infections with pathogens such as HIV, HCV, or HAV [7]. Examples of high-risk sexual behaviour include sex while intoxicated or sex in exchange for goods and services such as money, shelter, or drugs. [20]

Inadequate living situations can cause physical injuries that increase susceptibility to infections. For example, a wheelchairbound person may develop sacral pressure injuries due to lack of an adequate place to lie down. Treatment for these wounds can be delayed due to lack of access to care, which can result in serious life-threatening infection requiring hospital admission. Increased susceptibility to infection can also be the result of poorly controlled comorbid health conditions, such as diabetes. All these environmental and host-specific risks are interrelated and may have multiplicative effects, leading to a substantial increase in the risk of disease.

\section{Recent examples from California: communicable disease among PEH}

Accurate measurement of communicable disease burden among California's population of PEH is challenging. Many communicable diseases linked to homelessness are not reportable conditions (e.g., norovirus illness). Housing status is not collected by routine surveillance systems for all communicable diseases. Nevertheless, data are available from routine surveillance at California Department of Public Health (CDPH) for several communicable diseases that illustrate the disproportionate burden of 


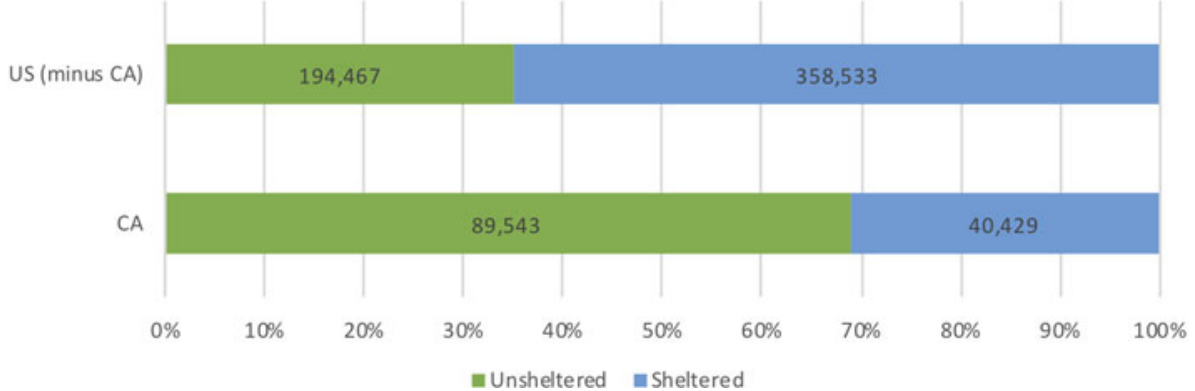

Fig. 3. Unsheltered vs. sheltered status among persons experiencing homelessness in California and the USA. communicable diseases among PEH in California (Table 2). We summarise examples of communicable diseases among $\mathrm{PEH}$ in California to describe transmission dynamics, the risks encountered by $\mathrm{PEH}$ and the public health response. The selected examples represent common communicable diseases with available surveillance or cross-sectional data. Other diseases that disproportionately affect $\mathrm{PEH}$ that are not presented include lousetransmitted Bartonella quintana infection, which has been previously described in a case series outside of the USA [21].

\section{Hepatitis A}

Hepatitis A, caused by the hepatitis A virus (HAV), usually causes a mild, self-limiting illness for which supportive measures are the standard of care [16]. Community-based transmission is now uncommon in the US and a rapid decrease in hepatitis A incidence after the introduction of hepatitis A vaccination in 1996 suggests that immunisation played an important role [16]. However, since 2017, the Centres for Disease Control (CDC) has reported outbreaks of hepatitis $\mathrm{A}$ in 30 states including California among people who use drugs, people who are experiencing unstable housing or homelessness and men who have sex with men [22]. In California, the hepatitis A vaccine is universally recommended for children and adults at increased risk of infection as specified by the Advisory Committee on Immunisation Practices (ACIP). The California Department of Public Health and local health departments also use the hepatitis A vaccine to respond to hepatitis A outbreaks.

During 2016-2018, California experienced a large hepatitis A outbreak among $\mathrm{PEH}$ that was concentrated in San Diego County. This outbreak was the largest hepatitis A outbreak in California since the introduction of hepatitis A vaccination. Statewide, a total of 708 outbreak-related hepatitis A cases were reported, with 465 hospitalisations (66\%) and 21 deaths (3\%). More than half of cases $(52.6 \%, n=372)$ were in PEH. The outbreak did not involve the general population and predominantly affected $\mathrm{PEH}$ and/or who were using drugs. Of the $\mathrm{PEH}$ who developed hepatitis A, more than two-thirds $(71.6 \%, n=263)$ also reported drug use. This outbreak was notable for the high rate of hospitalisation and death [23]. For comparison, a multistate outbreak of hepatitis A tied to consumption of frozen strawberries in 2016 was linked to 143 cases, 56 hospitalisations (39\%) and no deaths [24].

Several factors drove the California outbreak of hepatitis A among $\mathrm{PEH}$, including underlying risk factors, environmental sanitation, and vaccine acceptability and access. $\mathrm{PEH}$ were at risk for developing hepatitis A due to exposure to unsanitary conditions and concomitant drug use. PEH were at increased risk of severe disease due to underlying alcohol use disorder and chronic
HCV infection. Of people with outbreak-associated hepatitis A, $17 \%$ were positive for either $\mathrm{HCV}$ antibody (anti-HCV) indicating past or current infection, or HCV RNA indicating current infection. Similarly, the prevalence was high in three other states that experienced hepatitis A outbreaks that affected $\mathrm{PEH}$ and people who use drugs in 2017: 49\% (29/59) in Kentucky, 26\% (165/ 632) in Michigan and 21\% (31/148) in Utah [25].

In the general population, the prevalence of anti-HCV and HCV RNA positivity in the USA is $1.7 \%$ and $1 \%$, respectively [26]. Hepatitis A outbreaks are difficult to control due to the long incubation interval, long period of infectivity and a significant proportion of asymptomatic infections. Public health agencies in California used three population-level strategies to respond to the outbreak of hepatitis A among PEH: vaccination, sanitation, and education. Vaccination efforts targeted at-risk individuals ( $\mathrm{PEH}$ or persons using drugs and living in unstable housing). During this outbreak, the CDPH expanded criteria for hepatitis A vaccination beyond ACIP recommendations, which at the time did not include PEH, to include PEH [27]. Reaching at-risk individuals required partnerships with local organisations, since many people lived in less accessible locations and experienced a lack of trust in the healthcare system. For example, San Diego County public health nurses worked with staff from homeless service providers or law enforcement to form 'foot teams' and reach at-risk individuals in riverbeds, canyons, ravines, parks, and urban encampments. In San Diego County alone, 121921 hepatitis A vaccinations were delivered during this outbreak [28]. To support vaccination efforts, California Governor Jerry Brown declared a state of emergency in October 2017, which enabled the state to ensure adequate vaccine supply for outbreak response [29]. Sanitation interventions included increasing access to bathrooms by extending hours of bathroom facilities and setting up portable toilets and handwashing stations. Education interventions were aimed at high-risk populations, health care providers and the general public. Specific tools included pamphlets explaining the role of hygiene in interrupting disease transmission and hygiene kits. Collaboration with local media outlets was critical for the dissemination of these messages.

The California hepatitis A outbreak ended in 2018, but other outbreaks are ongoing in the USA. In February 2019, ACIP updated its recommendations for hepatitis A vaccination to include PEH [30]. ACIP recommends routine hepatitis A vaccination in children [31] and adults with risk factors, including homelessness, chronic liver disease, clotting factor disorders, men who have sex with men, work with HAV in a research laboratory, travel in countries with high or intermediate endemic hepatitis $\mathrm{A}$, or close personal contact of an international adoptee [32]. Delivering the hepatitis A vaccine to this population remains a challenge, particularly given the existing challenges $\mathrm{PEH}$ face 
Table 1. Major risk factors and communicable diseases identified among people experiencing homelessness

\begin{tabular}{|c|c|c|}
\hline Risk factor & Modes of disease transmission & Communicable disease (examples) \\
\hline \multicolumn{3}{|l|}{ Inadequate access to personal hygiene } \\
\hline Handwashing and toilet facilities & - Fecal-oral & $\begin{array}{l}\text { - Hepatitis A } \\
\text { - Shigella } \\
\text { - Norovirus }\end{array}$ \\
\hline Bathing and skin care & - Direct inoculation & $\begin{array}{l}\text { - Skin and soft tissue infections (SSTIs) } \\
\text { - Group A streptococcal infections }\end{array}$ \\
\hline Laundry & $\begin{array}{l}\text { - Ectoparasite infestations } \\
\text { - Vector-borne illnesses }\end{array}$ & $\begin{array}{l}\text { - Lice } \\
\text { - Scabies } \\
\text { - Bed bugs } \\
\text { - Bartonella quintana (louse-borne) }\end{array}$ \\
\hline \multicolumn{3}{|l|}{ Inadequate access to resting places } \\
\hline Pressure injury from lying on hard surfaces & - Direct contact & - SSTIS \\
\hline $\begin{array}{l}\text { Lower extremity stasis dermatitis from lack of } \\
\text { places to lie flat }\end{array}$ & - Direct contact & - SSTIS \\
\hline $\begin{array}{l}\text { Congregate settings and increased exposures } \\
\text { (shelters, tent dwellings) }\end{array}$ & $\begin{array}{l}\text { - Droplet } \\
\text { - Airborne } \\
\text { - Direct contact } \\
\text { - Fomites }\end{array}$ & $\begin{array}{l}\text { - Norovirus } \\
\text { - Influenza } \\
\text { - Tuberculosis } \\
\text { - Hepatitis A }\end{array}$ \\
\hline Exposure to disease vectors & - Vector-borne & - Mosquito-borne illnesses, Typhus (flea-borne) \\
\hline \multicolumn{3}{|l|}{ Behavioral risks } \\
\hline $\begin{array}{l}\text { Exchange of sex for money } \\
\text { Sex while high } \\
\text { Sexual assault }\end{array}$ & - Sexual contact & $\begin{array}{l}\text { - Syphilis } \\
\text { - Gonorrhea } \\
\text { - Chlamydia } \\
\text { - HIV } \\
\text { - Hepatitis B }\end{array}$ \\
\hline \multicolumn{3}{|l|}{ Comorbid medical conditions } \\
\hline $\begin{array}{l}\text { Substance abuse, including alcohol, intravenous } \\
\text { drug use }\end{array}$ & $\begin{array}{l}\text { - Blood-borne } \\
\text { - Skin disruption }\end{array}$ & $\begin{array}{l}\text { - HIV } \\
\text { - Hepatitis A } \\
\text { - Hepatitis B } \\
\text { - Hepatitis C } \\
\text { - Invasive group A streptococcal infections } \\
\text { - Methicillin resistant Staphylococcus aureus }\end{array}$ \\
\hline Mental illness & $\begin{array}{l}\text { - Increase risk behavior } \\
\text { - Decreased self-care } \\
\text { - Delays in care }\end{array}$ & May exacerbate multiple conditions \\
\hline \multicolumn{3}{|l|}{ Limited access to healthcare } \\
\hline Limited preventive services & $\begin{array}{l}\text { - Decreased vaccinations } \\
\text { - Increased vulnerability to } \\
\text { infections }\end{array}$ & $\begin{array}{l}\text { - Shingles } \\
\text { - Pneumonia } \\
\text { - Hepatitis A }\end{array}$ \\
\hline Poorly controlled chronic conditions & $\begin{array}{l}\text { - Decreased immunity } \\
\text { - Increased vulnerability to } \\
\text { infections }\end{array}$ & - SSTIS \\
\hline Low health literacy & - Delays in care & \\
\hline
\end{tabular}


Table 1. (Continued.)

\begin{tabular}{|c|c|c|}
\hline Risk factor & Modes of disease transmission & Communicable disease (examples) \\
\hline & & $\begin{array}{l}\text { - Pneumonia requiring hospitalisation due to late } \\
\text { presentation }\end{array}$ \\
\hline Limited medical care & $\begin{array}{l}\text { - Decreased secondary and } \\
\text { tertiary prevention } \\
\text { - Lack of treatment due to } \\
\text { inability to find affected } \\
\text { individuals }\end{array}$ & $\begin{array}{l}\text { Severe sequelae of minor medical issues. For example, } \\
\text { septic shock from cellulitis related to infected wounds from } \\
\text { venous stasis dermatitis. }\end{array}$ \\
\hline
\end{tabular}

when accessing medical care. One potential delivery mechanism is via requirements imposed by California Senate Bill 1152 (SB1152), which requires hospitals to offer appropriate vaccinations to homeless patients on inpatient or emergency room discharge [33].

\section{Syphilis}

Syphilis, a sexually transmitted genital ulcerative disease caused by the bacterium Treponema pallidum, is associated with significant adverse consequences if left untreated with progression into secondary and tertiary syphilis. The incidence of syphilis has increased nationally and in California despite the usual efforts of public health departments, which includes contact tracing, screening, and treatment with penicillin [34,35]. In 2017, the incidence rate of primary and secondary syphilis was 16.8 cases per 100000 Californians, up from 1.0 cases per 100000 in 2000 [36]. Among women, cases increased by $600 \%$ during $2012-$ 2017 [37]. Homelessness disproportionately affects people with syphilis: $7 \%$ of men and $21 \%$ of women in California with a new diagnosis of syphilis during 2017-2018 [38]. In comparison, $\mathrm{PEH}$ represent $0.3 \%$ of California's total population. The significant burden of homelessness in women is particularly concerning in light of the rise in congenital syphilis (CS) cases in California. Previous work in other states on mothers of infants with CS indicates that unstable housing status is associated with increased risk of CS [39, 40]. Outbreaks of syphilis have also occurred among PEH. In 2018, Sonoma County identified a cluster of syphilis cases among homeless individuals living in encampments [41]. In response, Sonoma County Department of Public Health initiated targeted screening efforts both in the field and through providers serving persons at increased risk in order to identify additional cases and provide treatment.

The association between homelessness and syphilis may be related to multiple intersecting factors. For example, substance use disorders, which are common among PEH [7] and sex while high has been associated with increased risk of syphilis in women [42]. Lack of access to care and inadequate screening and treatment, which are also common among $\mathrm{PEH}$ [7], may result in continued spread within sexual networks. PEH may exchange sex for services or goods [43] and these activities increase the risk for sexually transmitted infections, such as syphilis, due to a large number of partners and inability to negotiate consistent condom use [44]. Current efforts to address the rising rates of syphilis in the general population include expansion of populations screened for syphilis in screening guidelines for sexually transmitted infections and targeted screening interventions.
Current CDC guidelines recommend syphilis screening for all pregnant women, sexually active MSM, men at increased risk and HIV positive individuals [45]. One example of a targeted screening intervention that could reduce the burden of syphilis is to increase screening in the correctional system. In California state prisons all inmates are screened for syphilis and treated if syphilis is diagnosed. The California Department of Public Health encourages providers serving $\mathrm{PEH}$, including hospital emergency departments, to provide sexually transmitted disease screening for PEH.

\section{Invasive group A streptococcal infections}

Group A Streptococcus (GAS) bacteria cause a variety of minor infections, including pharyngitis and skin infections. Invasive group A streptococcal infection (iGAS) is defined as infection with GAS isolation from a normally sterile site (blood) or wound with necrotizing fasciitis or streptococcal toxic shock syndrome [46]. The CDC tracks cases through the Active Bacterial Core surveillance (ABCs) system, which collects data on several pathogens, including Group A Streptococcus, from sites in 10 states, including three counties in California [47]. iGAS is associated with increased mortality (case fatality ratio $11.7 \%$ ). Factors independently associated with death included increasing age and underlying chronic illness [48]. Outbreaks of iGAS have been described among individuals experiencing homelessness and/or individuals who use injection drugs in Europe [49], Canada [50] and the USA [51].

While iGAS is not routinely reportable in California, a study of 673 iGAS cases in San Francisco during 2010-2017 tracked by the $\mathrm{ABCs}$ system found that $34 \%$ of cases were among PEH. The incidence of iGAS increased significantly from 300 in 2010-2014 to 547 in 2017 per 100000 population among $\mathrm{PEH}$ and from 5 in 2010-2013 to 9.3 in 2017 per 100000 among people not experiencing homelessness. The iGAS incidence was greater among $\mathrm{PEH}$ compared to people not experiencing homelessness due to multiple risk factors, including substance use disorders and barriers to appropriate skin care [46]. Individuals who use injection drugs may develop infections from contaminated drugs, needles, or drug paraphernalia. Recent work from New Mexico evaluating risk factors for iGAS among PEH suggested that skin breakdown and barriers to appropriate skin care may increase the risk of iGAS [52]. Collaboration with organisations serving $\mathrm{PEH}$ and people who inject drugs, such as needle exchange organisations, is important for preventing infections in this population and for providing care to limit the severity of wounds that have already developed. For example, existing needle exchange services not 
Table 2. Recent reports describing housing status and major communicable diseases in California

\begin{tabular}{|c|c|c|c|c|c|c|c|}
\hline Category (reference) & $\begin{array}{l}\text { People experiencing } \\
\text { homelessness } N\end{array}$ & $\begin{array}{l}\text { Homeless } \\
\text { per cent } \%\end{array}$ & $\begin{array}{c}\text { People not } \\
\text { experiencing } \\
\text { homelessness } N\end{array}$ & $\begin{array}{l}\text { Non-homeless } \\
\text { per cent } \%\end{array}$ & $\begin{array}{l}\text { Total } \\
\text { population } n\end{array}$ & Data type & Location \\
\hline California population $[4,6]$ & 129972 & 0.3 & 39427073 & 99.7 & 39557045 & $\begin{array}{l}\text { Homeless point in time } \\
\text { count, Census bureau }\end{array}$ & All California \\
\hline Hepatitis A Outbreak, 2017-2018 [23] & 372 & 52.6 & 335 & 47.4 & 707 & Outbreak investigation & $\begin{array}{l}\text { All California ( } 84 \% \text { of cases from San } \\
\text { Diego County) }\end{array}$ \\
\hline $\begin{array}{l}\text { Invasive Group A Streptococcal } \\
\text { Infections, 2010-2017 [50] }\end{array}$ & 299 & 44.4 & 374 & 55.6 & 673 & $\begin{array}{l}\text { CDC Active Bacterial } \\
\text { Core surveillance } \\
\text { (ABCs) }\end{array}$ & San Francisco County \\
\hline Hepatitis C 2016-2018, [67] & 680 & 32.9 & 1384 & 67.1 & 2064 & $\begin{array}{l}\text { CDPH linkage to care } \\
\text { demonstration project }\end{array}$ & $\begin{array}{l}\text { San Francisco County, San Diego } \\
\text { County, Los Angeles County, San Luis } \\
\text { Obispo County, and Monterey County }\end{array}$ \\
\hline $\begin{array}{l}\text { Primary and Secondary Syphilis } \\
\text { (Female), 2017-2018 [38] }\end{array}$ & 207 & 22.0 & 735 & 78.0 & 942 & Surveillance & $\begin{array}{l}\text { California Project Area (all California } \\
\text { counties except Los Angeles County } \\
\text { and San Francisco County) }\end{array}$ \\
\hline $\begin{array}{l}\text { Primary and Secondary Syphilis } \\
\text { (Male), 2017-2018 [38] }\end{array}$ & 275 & 6.6 & 3902 & 93.4 & 4177 & Surveillance & California Project Area \\
\hline Tuberculosis, 2017 [55] & 106 & 5.4 & 1873 & 94.6 & 1979 & Surveillance & All California \\
\hline $\begin{array}{l}\text { New HIV diagnoses within the last } \\
12 \text { months, 2012-2017 [58] }\end{array}$ & 378 & 1.3 & 29826 & 98.7 & 30204 & Surveillance & All California \\
\hline
\end{tabular}

Data are routine disease monitoring data unless otherwise noted. 
only provide needles and syringes but also educate people on appropriate skin care and harm reduction methods [53].

\section{Tuberculosis}

TB is caused by Mycobacterium tuberculosis and commonly causes pulmonary infections or asymptomatic latent infection. The TB incidence rate nationally among people experiencing homeless was estimated from 36 to 47 cases per 100000 population in 2006-2010 [54], compared to 2.8 per 100000 population in the general population in 2017 [55]. While TB is more common in $\mathrm{PEH}$ than the general population, multi-drug resistant (MDR) TB was less common. MDR infections affected $1 \%$ of $\mathrm{PEH}$ with TB [54], compared to $1.9 \%$ of all people diagnosed with TB in the US in 2018 [56]. Among patients with TB in $2017,5.6 \%$ of TB cases in California reported homelessness, compared to $4.6 \%$ nationally [55]. In California, using the point in time estimate of the population of $\mathrm{PEH}$, the incidence rate of TB among PEH in 2017 was 94 per 100000 population compared to 4.7 per 100000 population in the general population.

Los Angeles County has been experiencing a large TB outbreak among PEH since 2013. Efforts to address TB among PEH in Los Angeles County have had some success; the percentage of TB cases reporting homelessness declined from $10.1 \%$ in 2013 to $7.6 \%$ in 2016 [57]. Using the point in time estimate for the denominator, the incidence of TB among $\mathrm{PEH}$ decreased from 132 per 100000 population in 2013 to 89 per 100000 population in 2016. Los Angeles County Department of Public Health has collaborated with medical providers serving $\mathrm{PEH}$ and shelter sites to provide TB symptom screening at shelter entry, targeted testing, and TB treatment. The Agency also has a programme to temporarily house high-risk individuals receiving latent $\mathrm{TB}$ infection treatment [57].

There remain significant challenges to the treatment of active TB and latent TB infection among PEH. First, current information systems may not accurately reflect a person's true housing status, especially for people with unstable housing who may be intermittently homeless and housed. Therefore, reaching exposed individuals remains a challenge as contact tracing is difficult due to the lack of or transient living addresses of PEH. CDPH has successfully used external data from the HUD's Homeless Management Information System (HMIS) to assist with locating potential contacts. However, this information is imperfect, as people change locations over time. Second, adherence to treatment is a major challenge given the extended duration of therapy. For patients with latent TB infection, short-course therapy with rifapentine can help address issues with non-adherence due to length of therapy. Finally, exposures in congregate living situations such as homeless shelters may increase the risk of TB exposure among $\mathrm{PEH}$.

\section{HIV infection}

HIV infection is no longer the leading cause of death among $\mathrm{PEH}$ [11]. While no recent outbreaks have been reported in California, $\mathrm{PEH}$ experience a disproportionate burden of new HIV infection diagnoses. In California, from 2012 to 2017 across all counties, $1.3 \%(378 / 30204)$ of new cases of HIV infection were in people identified as experiencing homelessness or unstable housing based on home address [58]. During the same period, $1 \%$ of people living with HIV were homeless or unstably housed [59]. Data from the Medical Monitoring Project (MMP) in California, which includes data for all counties except for San Francisco and Los
Angeles, estimates that $10.8 \%$ (95\% CI 6.7-14.9\%) of California adults living with HIV reported homelessness during the 12 months before the interview [60]. The difference in the estimates may be related to the differences in data collection. Surveillance data include all counties in California, while the MMP includes all counties except for San Francisco and Los Angeles. Surveillance data measure housing status at a point in time based on the classification of a patient's home address, while the MMP asks people directly about their housing status over the past year. In 2017, based on the point in time population of $\mathrm{PEH}$, the incidence rate of newly diagnosed HIV infection among $\mathrm{PEH}$ in California was nearly fivefold that of the general population: 56 cases per 100000 population among PEH compared to 12 cases per 100000 population in the general population. In San Francisco, 14\% of new HIV infection cases were among $\mathrm{PEH}$, and $\mathrm{PEH}$ had delays in time to viral suppression compared to those who were not homeless [61].

Previous research demonstrates that housing decreases mortality among people living with HIV [62]. Several programmes help $\mathrm{PEH}$ who have HIV infection to find housing, including the Ryan White programme [63] and the Housing Opportunities for Persons with AIDS Programme administered by the US Department of HUD [64]. Collaboration with local governments and organisations is key to meeting the needs of this population. In San Francisco, the Getting to Zero initiative advocates for people living with HIV to be prioritised for housing [65]. In 2018, San Francisco Department of Public Health received CDC funding for Project OPT-IN, a 4-year demonstration project to improve HIV treatment outcomes among vulnerable populations, including PEH. Proposed services include homeless outreach and intensive care management. [66]

\section{Hepatitis C}

Hepatitis C disproportionately affects PEH [13]. In California, housing status is not routinely collected by the hepatitis $\mathrm{C}$ disease monitoring system. Information on hepatitis $\mathrm{C}$ and housing status comes from California Department of Public Health's hepatitis C testing and linkage to care demonstration projects in four sites serving five counties (San Luis Obispo, Monterey, San Francisco, San Diego and Los Angeles), which found that out of 2064 individuals who newly tested positive for HCV RNA between 1 March 2016 and 30 June 2019, 32.9\% (680) were known to be unstably housed [67]. While these data are unlikely to be generalisable to all persons testing positive for HCV since they specifically targeted PEH and people who use injection drugs, they suggest that homelessness may be common among persons infected with HCV in California. Unstable housing is a common barrier to hepatitis $\mathrm{C}$ treatment. Collaboration with local organisations and governments is important to find innovative ways to reach $\mathrm{PEH}$ who have hepatitis $\mathrm{C}$ infection. This is already at work in San Francisco: the End Hep C SF campaign aims to ensure access to hepatitis $\mathrm{C}$ treatment for all people, including PEH. This collaborative effort involves the San Francisco Department of Public Health, community clinics and homeless shelters that offer on-site hepatitis $C$ treatment. [68]

\section{Policy implications}

There are multiple potential factors that increase the risk of homelessness and potential areas in which to intervene. 
Housing: Preventing homelessness and providing housing for $\mathrm{PEH}$ can eliminate many of the risks that $\mathrm{PEH}$ face. Housing decreases mortality among people with HIV [62] and programs now exist to provide housing for this population. Limited evidence suggests that housing will be beneficial for other groups as well: among chronically ill homeless adults, permanent supportive housing was associated with decreased mortality. Only $2 \%$ of the housed individuals died of infectious causes compared to $13 \%$ of unhoused individuals [69]. Permanent supportive housing programmes provide a suite of healthcare and social services to help individuals stay healthy and housed [69]. For example, treatment of comorbid substance use disorders and mental illness can help decrease the risk of communicable diseases and increase a person's capacity for self-care. [7]

States have experimented with using Medicaid dollars to pay for housing [5], but addressing the root causes of homelessness, including addressing issues of affordable housing, are fundamental for mitigating the risks to health among PEH.

Improving care for $\mathrm{PEH}$ : Efforts to improve access to healthcare for $\mathrm{PEH}$ could prevent or mitigate illness in more individuals. One strategy is recent California legislation (SB1152) which mandates hospitals to offer appropriate vaccinations and coordination of care for homeless patients on hospital or emergency room discharge. Another strategy is the California Whole Person Care pilot program that is intended to enhance coordination of health and social services for vulnerable populations including $\mathrm{PEH}$.

Improving information systems: Reaching exposed or at-risk individuals remains a major challenge, especially when these individuals do not have permanent contact information. Use of information systems like the California Immunisation Registry (CAIR) [70] and the HUD's HMIS [71] could support improved information sharing between different homeless service providers and public health departments to reach people in a timely fashion and provide needed services [72]. The Health Insurance Portability and Accountability Act protects certain health information and may be a barrier for health care systems to collaborate with homeless service providers. [73]

Strengthening partnerships: Public health departments must work closely in partnership with local governments and nongovernmental organisations to meet the health needs of $\mathrm{PEH}$. One important group of partners are community health centres that receive funding through the federal Health Care for the Homeless program. In the case of the 2017-2018 hepatitis A outbreak, collaboration between the department of public health and local social services agencies was crucial for reaching thousands of at-risk individuals.

\section{Summary}

California has a large and growing population of PEH. Compared to the rest of the country, California's population of $\mathrm{PEH}$ are disproportionately unsheltered and chronically homeless. These individuals die prematurely and suffer a greater burden of illness, including communicable diseases such as HIV, hepatitis A, hepatitis $\mathrm{C}$ and TB. PEH are especially vulnerable due to the intersection of multiple risks, including increased exposure to pathogens, decreased immunity and decreased access to healthcare and services that would mitigate the severity of illness.

There are several important limitations to the available data on housing status and communicable disease risk. First, disease incidence among PEH may be overestimated due to undercounting of the true population of the $\mathrm{PEH}$. Calculations of disease incidence rely on HUD's yearly point-in-time counts, which may fail to include people in hard to reach locations (riverbeds, remote encampments) and people intermittently cycling between homelessness and unstable temporary housing arrangements. Second, case burdens may appear elevated due to enhanced screening among PEH. For example, targeted syphilis screening among $\mathrm{PEH}$ in Sonoma County may partly explain the elevated proportion of $\mathrm{PEH}$ among people with syphilis. Conversely, it also may be the case that $\mathrm{PEH}$ are not properly identified due to lack of medical care or inability to trace contacts due to lack of information. Finally, housing status is inconsistently collected across disease categories and a significant amount of housing information is missing, which can affect disease incidence estimates in either direction.

Efforts to address communicable disease risk in this population will depend on innovative strategies to overcome the unique challenges in reaching people and providing adequate treatment, as well as strategies to address fundamental causes related to access to affordable housing and treatment for comorbid conditions including substance use disorder and mental illness. While some of the root causes of homelessness lie outside the purview of public health agencies, there are opportunities for public health to support both primary and secondary prevention of communicable disease issues in $\mathrm{PEH}$. Examples of primary prevention efforts by public health include immunisation, promotion of harm reduction methods including needle exchange and efforts to increase access to mental health services, substance use treatment and supportive services for PEH. Examples of potential secondary prevention interventions include supporting access to culturally competent clinical and other supportive services to reduce the complications of infections once they occur.

Acknowledgements. Tambi Shaw, Anna Flynn, Deanna Sykes, Philip Peters, Anna Branzuela, Ryan Murphy provided advice and data for this manuscript.

This activity received no specific grant from any funding agency, commercial or not-for-profit sectors.

Conflict of interest. None.

\section{References}

1. Public Health Service Act. Section 330. 42 U.S.C. $\$ 254($ b). Available at https://www.law.cornell.edu/uscode/text/42/254b.

2. United States Department of Housing and Urban Development (2011) Homeless Emergency Assistance and Rapid Transition to Housing (HEARTH) Act. Federal Register 76, 75994-76019.

3. National Law Center on Homelessness \& Poverty (2018) Homelessness in America: overview of data and causes.

4. Henry M et al. (2018) The 2018 Annual Homeless Assessment Report (AHAR) to Congress, Part 1: point-in-time estimates of homelessness. Available at https://www.hudexchange.info/resources/documents/2018AHAR-Part-1.pdf.

5. National Academies of Sciences Engineering and Medicine (2018) Permanent Supportive Housing: Evaluating the Evidence for Improving Health Outcomes Among People Experiencing Chronic Homelessness. Washington, DC: The National Academies Press.

6. U.S. Census Bureau. U.S. Census Bureau QuickFacts: California Population 2018. Accessed 2 August 2019. Available at https://www.census.gov/quickfacts/CA.

7. Fazel S, Geddes JR and Kushel M. The health of homeless people in highincome countries: descriptive epidemiology, health consequences, and clinical and policy recommendations. The Lancet 2014;384(9953):1529-1540.

8. Auerswald CL, Lin JS and Parriott A (2016) Six-year mortality in a street-recruited cohort of homeless youth in San Francisco, California. PeerJ 4, e1909. 
9. Montgomery AE et al. (2016) Homelessness, unsheltered status, and risk factors for mortality: findings from the 100000 homes campaign. Public Health Reports 131, 765-772.

10. Roncarati JS et al. (2018) Mortality Among unsheltered homeless adults in Boston, Massachusetts, 2000-2009. JAMA Internal Medicine 178, 1242.

11. Baggett TP et al. (2013) Mortality among homeless adults in Boston. JAMA Internal Medicine 173, 189.

12. Khan K et al. (2011) Active tuberculosis among homeless persons, Toronto, Ontario, Canada, 1998-2007. Emerging Infectious Diseases 17, 357-365.

13. Fazel S, Beijer U and Wolf A (2012) Prevalence of tuberculosis, hepatitis $\mathrm{C}$ virus, and HIV in homeless people: a systematic review and meta-analysis. The Lancet Infectious Diseases 12, 859-870.

14. Centers for Disease Control and Prevention (2018) Tuberculosis and homelessness workshop on tuberculosis and homelessness: infection control measures in homeless shelters and other overnight facilities that provide shelter. Available at https:/www.cdc.gov/tb/topic/populations/ homelessness/TB_and_Homelessness_2015_Summit.pdf.

15. California Department of Public Health (2018) Norovirus recommendations for evacuation centers. Available at https://www.cdph.ca.gov/ Programs/CID/DCDC/CDPH DocumentLibrary/Norovirus_Evacuation_ Centers_20181115_Letterhead.pdf.

16. Centers for Disease Control and Prevention (2015) Hepatitis A. Epidemiology and prevention of vaccine-preventable diseases, 13th Ed. pp. 135-148. Available at https://www.cdc.gov/vaccines/pubs/pinkbook/downloads/hepa.pdf.

17. Raoult D, Foucault $\mathbf{C}$ and Brouqui $\mathbf{P}$ (2001) Infections in the homeless. The Lancet Infectious Diseases 1, 77-84.

18. O'Connell J, ed. (2004) The health care of homeless persons. Boston. https://www.bhchp.org/sites/default/files/BHCHPManual/index.html.

19. Badiaga S et al. (2005) Prevalence of skin infections in sheltered homeless. European Journal of Dermatology 15, 382-386.

20. Calsyn DA et al. (2010) Sex under the influence of drugs or alcohol: common for men in substance abuse treatment and associated with high-risk sexual behavior. American Journal on Addictions 19, 119-127.

21. Brouqui P et al. (2005) Ectoparasitism and vector-borne diseases in 930 homeless people from Marseilles. Medicine 84, 61-68.

22. Centers for Disease Control and Prevention. Outbreaks of hepatitis A in multiple states among people who use drugs and/or people experiencing homelessness. Accessed 14 January 2020. Available at https://www.cdc. gov/hepatitis/outbreaks/2017March-HepatitisA.htm.

23. California Department of Public Health. (2018) Hepatitis a outbreak associated with drug use and homelessness in California, 2016-2018. Available at https://www.cdph.ca.gov/Programs/CID/DCDC/CDPHDocument Library/ Immunization/2016-18CAOutbreakAssociatedDrugUseHomelessness.pdf.

24. Centers for Disease Control and Prevention (2016) Multistate outbreak of hepatitis A linked to frozen strawberries (Final Update). Accessed 15 March 2019. Available at https:/www.cdc.gov/hepatitis/outbreaks/2016/ hav-strawberries.htm.

25. Foster M et al. (2017) Hepatitis a virus outbreaks associated with drug use and homelessness-California, Kentucky, Michigan, and Utah, 2017. Morbidity and Mortality Weekly Report. Available at https://www.cdc. gov/mmwr/volumes/67/wr/mm6743a3.htm.

26. Hofmeister MG et al. (2019) Estimating prevalence of hepatitis C virus infection in the United States, 2013-2016. Hepatology 69, 1020-1031.

27. California Department of Public Health (2017) All facilities letter: California hepatitis a outbreaks and use of hepatitis a vaccine for at-risk patients and health care personnel. Accessed 2 August 2019. Available at https://www.cdph.ca.gov/Programs/CHCQ/LCP/Pages/AFL-17-13.aspx.

28. County of San Diego (2018) Hepatitis a outbreak after action report. Available at https://www.sandiegocounty.gov/content/dam/sdc/cosd/SanDiegoHepatitisA Outbreak-2017-18-AfterActionReport.pdf.

29. Spagat E (2017) Gov. Jerry Brown declares state of emergency in California over hepatitis A outbreak. USA Today. Available at https:// www.usatoday.com/story/news/nation/2017/10/13/california-state-of-emergencyhepatitis-a-outbreak/763722001/.

30. Advisory Committee on Immunization Practices. GRADE Hepatitis A vaccine for persons experiencing homelessness. https://www.cdc.gov/ vaccines/acip/recs/grade/hav-homeless-H.pdf.
31. Centers for Disease Control and Prevention (2019) Recommended child and adolescent immunization schedule for ages 18 years or younger. Available at http://www.acog.org.

32. Centers for Disease Control and Prevention (2019) Recommended adult immunization schedule 2019. Available at https:/www.cdc.gov/vaccines/ schedules/downloads/adult/adult-combined-schedule.pdf.

33. State of California (2018) Senate Bill No. 1152: Hospital patient discharge process: homeless patients.

34. Centers for Disease Control and Prevention (2018) Sexually transmitted disease surveillance 2017. Available at https://www.cdc.gov/std/stats17/ 2017-STD-Surveillance-Report_CDC-clearance-9.10.18.pdf.

35. Centers for Disease Control and Prevention (2015) Sexually transmitted diseases treatment guidelines, 2015. Morbidity and Mortality Weekly Report 64, 36.

36. California Department of Public Health (2017) All STDs Tables California, 2017. Available at https://www.cdph.ca.gov/Programs/CID/ DCDC/CDPH Document Library/STD-Data-All-STDs-Tables.pdf.

37. California Department of Public Health. Sexually transmitted diseases in California: 2017 Snapshot. Available at https:/www.cdph.ca.gov/Programs/ CID/DCDC/CDPH\%20Document Library/STDs-CA-2017Snapshot.pdf.

38. California Department of Public Health (2018) Housing status among syphilis cases, 2017-2018 (Unpublished Data).

39. Diorio D, Kroeger K and Ross A (2018) Social vulnerability in congenital syphilis case mothers: qualitative assessment of cases in Indiana, 2014 to 2016. Sexually Transmitted Diseases 45, 447-451.

40. Slutsker JS, Hennessy RR and Schillinger JA (2018) Factors contributing to congenital syphilis cases - New York city, 2010-2016. Morbidity and Mortality Weekly Report 67, 1088-1093.

41. Sonoma County Department of Public Health (2018) Health Advisory: Continued Increase in Syphilis Cases. Accessed 3 May 2019. Available at https://sonomacounty.ca.gov/Health/Public-Health/Disease-Control/HealthAdvisory-Continued-Increase-in-Syphilis-Cases-January-29-2018/.

42. Kidd SE et al. (2019) Increased methamphetamine, injection drug, and heroin use among women and heterosexual men with primary and secondary syphilis - United States, 2013-2017. Morbidity and Mortality Weekly Report 68, 144-148.

43. Weiser SD et al. (2006) Gender-specific correlates of sex trade among homeless and marginally housed individuals in San Francisco. Journal of Urban Health 83, 736-740.

44. World Health Organization (2012) Sex workers and syphilis. World Health Organization; Accessed 14 January 2020. Available at https:// www.who.int/gho/sti/sex_workers/text/en/.

45. Centers for Disease Control and Prevention. 2015 STD treatment guidelines. Accessed 23 April 2019. Available at https://www.cdc.gov/std/ tg2015/screening-recommendations.htm.

46. Scheuer $\mathbf{T}$ et al. LB9. Rising high rate of invasive group A Streptococcus infections among persons experiencing homelessness in San Francisco, 2010-2017. Open Forum Infectious Diseases 2018;5 (suppl.1), S762-S762.

47. Centers for Disease Control and Prevention. Group A Strep. Accessed 15 March 2019. Available at https://www.cdc.gov/groupastrep/surveillance. html.

48. Nelson GE et al. (2016) Epidemiology of invasive group a streptococcal infections in the United States, 2005-2012. Clinical Infectious Diseases. NIH Public Access; 63, 478-486.

49. Luczkowiak J et al. Clonal Spread of Streptococcus pyogenes emm44 among Homeless Persons, Rennes, France. Available at http://www.sfm. asso.fr.

50. Athey TBT et al. (2016) High incidence of invasive group A streptococcus disease caused by strains of uncommon emm types in thunder Bay, Ontario, Canada. Journal of clinical microbiology 54, 83-92.

51. Mosites E et al. (2018) Outbreak of invasive infections from subtype emm26.3 group A streptococcus among homeless adults - anchorage, Alaska, 2016-2017. Clinical Infectious Diseases 66, 1068-1074.

52. Valenciano SJ et al. (2019) Notes from the field: identifying risk behaviors for invasive group A streptococcus infections among persons who inject drugs and persons experiencing homelessness - New Mexico, May 2018. Morbidity and Mortality Weekly Report 68, 205-206. 
53. San Francisco AIDS Foundation. Syringe access site schedule. Accessed 23 April 2019. Available at http://sfaf.org/client-services/syringe-access/ site-schedule.html.

54. Bamrah S et al. (2013) Tuberculosis among the homeless, United States, 1994-2010. International Journal of Tuberculosis and Lung Disease 17, 1414-1419.

55. Centers for Disease Control and Prevention (2018) Reported Tuberculosis in the United States, 2017: Table 38. Tuberculosis Cases and Percentages, by Homeless Status, Ages $\geq 15$ Years: Reporting Areas, 2017. Available at https://www.cdc.gov/tb/statistics/reports/2017/table38. htm.

56. Talwar A et al. (2019) Tuberculosis - United States, 2018. Vol. 68, Morbidity and Mortality Weekly Report. Available at https://www.

57. Los Angeles County Department of Public Health (2018) Tuberculosis in Los Angeles County: Surveillance Report 2016. Available at http://publichealth.lacounty.gov/tb/docs/SurveillanceReport2016.pdf.

58. California Department of Public Health. Newly diagnosed HIV infections in California by housing status 2012-2017 (Unpublished Data).

59. California Department of Public Health. Persons living with HIV/AIDS in California by housing status 2012-2017 (Unpublished Data).

60. California Department of Public Health. Estimate of past year homelessness, Medical Monitoring Project (MMP) California Project Area 2015-2016 (Unpublished Data).

61. San Francisco Department of Public Health (2017) HIV Epidemiology annual report 2017. Available at https://www.sfdph.org/dph/comupg/ oprograms/HIVepiSec/HIVepiSecReports.asp.

62. Schwarcz SK et al. (2009) Impact of housing on the survival of persons with AIDS. BMC Public Health 9. http://www.biomedcentral.com/14712458/9/220.

63. United States Health Resources and Services Administration; About the Ryan White HIV/AIDS Program|HIV/AIDS Bureau. Accessed 15
August 2019. Available at https://hab.hrsa.gov/about-ryan-white-hivaidsprogram/about-ryan-white-hivaids-program.

64. U.S. Department of Housing and Urban Development. HOPWA: Housing Opportunities for Persons With AIDS - HUD Exchange. Accessed 2 August 2019. Available at https://www.hudexchange.info/programs/hopwa/.

65. Havlir D (2018) Housing needed to reduce HIV infections. San Francisco Chronicle. Available at https://www.sfchronicle.com/opinion/openforum/article/Housing-needed-to-reduce-HIV-infections-13432863.php?psid=E2hL.

66. Health Commission City and County of San Francisco (2018) Health commission meeting minutes, Tuesday, 6 November 2018. Available at http://www.sfdph.org.

67. California Department of Public Health (2018) Hepatitis C testing and linkage to care demonstration projects in California, March 2016-June 2018 (Unpublished Data).

68. End Hep CSF. Strategic plan. Accessed 3 May 2019. Available at http:// www.endhepcsf.org/strategic-plan-end-hep-c-sf/.

69. Henwood BF, Byrne T and Scriber B (2015) Examining mortality among formerly homeless adults enrolled in Housing First: An observational study. Available at https://www.ncbi.nlm.nih.gov/pmc/articles/PMC4669629/pdf/ 12889_2015_Article_2552.pdf.

70. California Immunization Registry. Accessed 14 May 2019. Available at http://cairweb.org/.

71. HMIS: Homeless Management Information System - HUD Exchange. Accessed 14 May 2019. Available at https://www.hudexchange.info/programs/hmis/.

72. U.S. Department of Housing and Urban Development. HMIS project descriptor data elements. Available at https://files.hudexchange.info/ resources/documents/HMIS-Project-Descriptor-Data-Elements-Manual.pdf.

73. United States Department of Health and Human Services (2019) Summary of the HIPAA security rule. Available at https:/www.hhs.gov/ hipaa/for-professionals/security/laws-regulations/index.html. 